\title{
VARIATIONS IN THE BRANCHING PATTERN OF THE CORDS OF THE BRACHIAL PLEXUS
}

\section{Prashant Moolya *.}

* Assistant Professor, Department of Anatomy, B.K.L.Walawalkar Rural Medical College, Savarde, Maharashtra, India.

\section{ABSTRACT}

Introduction: Brachial plexus has been the subject of various studies as it is an important nerve plexus at the junction of neck and upper limb. For procedures like neurotisation, nerve grafting and shoulder joint surgery by anterior approach, knowledge of brachial plexus and its variation will be helpful to prevent any iatrogenic trauma to the nerves. Aim of this study was to find out about the variation in the branching pattern of the cords of brachial plexus.

Methods: The present study was carried out by dissection of 120 (60 right and 60 left) upper limbs in 60 embalmed cadavers that were available in the department of Anatomy of Seth G. S. Medical College and KEM hospital Mumbai.

Result: Variations were encountered in the branching pattern of lateral and posterior cord, while medial cord branches did not show any variation.

Conclusion: Knowledge pertaining to the variation in the branching pattern of the cords of brachial plexus will guide the operating surgeon to prevent any iatrogenic trauma.

KEY WORDS: Lateral Cord, Posterior Cord, Medial Cord.

Address for Correspondence: Dr. Prashant Moolya, 217/1/2,Sumohan niwas, behind hotel Janata, budhuwarpeth, Madhavnagar, Sangli- 416406, , Maharashtra, India. Phone : 8087014123

E-Mail: pmsangli2@yahoo.co.in; prashantmmoolya@gmail.com

Access this Article online

Quick Response code

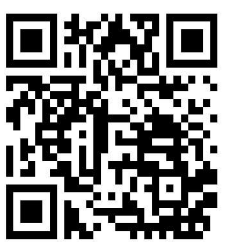

DOI: $10.16965 /$ ijar.2018.346

Journal Information

International Journal of Anatomy and Research

ICV for 2016 ISSN (E) 2321-4287 | ISSN (P) 2321-8967

90.30 https://www.ijmhr.org/ijar.htm DOI-Prefix: https://dx.doi.org/10.16965/ijar

\section{Article Information}

Received: 06 Aug 2018

Peer Review: 06 Aug 2018

Revised: None
Accepted: 06 Sep 2018

Published (O): 10 Oct 2018

Published (P): 10 Oct 2018

\section{INTRODUCTION}

Brachial plexus is the important nerve plexus at the junction of neck and upper limb hence it is widely used in different studies. Sushruta, has described the function of many components of peripheral nervous system by examining different injuries. Galen has contributed by differentiating nerves from tendon and by reporting the successful repair of nerves by other physicians [1].

The most common arrangement of brachial plexus is as follows, the fifth and sixth rami unite to form upper trunk at the lateral border of scalenus medius; the seventh cervical ramus forms the middle trunk; the eight cervical and first thoracic rami unite to form lower trunk behind scalenus anterior. The three trunks projects laterally, and behind the clavicle. Each of these trunks bifurcates into anterior and posterior divisions. The lateral cord is formed by the union of anterior divisions of upper and middle trunks. The medial cord is formed by the anterior division of the lower trunk, which often receives a branch from the seventh cervical ramus. Posterior cord is formed by the union of 
posterior divisions of all the three trunks [2].

For procedures like neurotisation [3], nerve grafting [3], shoulder joint surgery by anterior approach [4], knowledge of brachial plexus and any variation will be helpful to prevent any iatrogenic trauma to the nerves. Internal fixation of a humeral fracture by the common anterior approach and during other orthopaedic and neurosurgical procedures on cervical spine and prosthetic implant placements, knowledge of brachial plexus and its variations, is of utmost importance.

Aim: Aim of this study was to find out about the variation in the branching pattern of the cords of the brachial plexus.

\section{Objectives:}

1. To note any variation in the branching pattern of the lateral cord

2. To note any variation in the branching pattern of the medial cord

3. To note any variation in the branching pattern of the posterior cord

\section{MATERIALS AND METHODS}

The present study was carried out in the Department of Anatomy of Seth G. S. Medical College and KEM hospital Mumbai by dissection of 120 (60 right and 60 left) upper limbs in 60 embalmed cadavers that were available over a period of 2 years i.e. from 2012- 2014. All cadavers of both sexes available during the study period were included. In this study, 6 limbs (4 left and 2 right) were excluded because of damaged nerves and a fractured humerus. Dissection was done on the upper arm and axilla as per Cunningham's manual of practical Anatomy [5], using forceps, scalpel, and scissors. The skin, superficial fascia and deep fascia were dissected and the pectoralis major and pectoralis minor muscles were cut and reflected. The skin over the axillary region was incised and the fascia was reflected to uncover the axillary sheath, which surrounds the axillary vessels and brachial plexus. The axillary vein and its tributaries were identified and separated from the underlying axillary artery and brachial plexus. Then the axillary vein was cut along with the associated lymph nodes.
The infraclavicular part of the brachial plexus was dissected and exposed. The three cords of the brachial plexus (lateral, medial and posterior) were identified. Variation in the branching pattern of the brachial plexus was noted. The dissected specimens were numbered; photographs were taken and the observations were tabulated and statistically analysed.

\section{RESULTS}

114 upper limbs were dissected of which 58 were of a right side and 56 were of the left side. A hundred limbs belonged to male cadavers and fourteen limbs belonged to female cadavers. The ages of cadavers, at the time of death, ranged between 18 to 90 years.

Amongst the branches given by the lateral cord of the brachial plexus, the lateral pectoral nerve did not show any variations. The musculocutaneous nerve was totally absent bilaterally in 4 limbs ( 2 right and 2 left) and in 5 limbs even though the musculocutaneous nerve was present, it was not piercing the coracobrachialis muscle, such variation was present bilaterally in 2 cadavers ( 3 right and 2 left). Communication between musculocutaneous nerve and median nerve were noted in 23 upper limbs, in one limb (right side) communication was seen after piercing the coracobrachialis muscle and remaining 22 limbs (12 right and 10 left)showed communication before piercing the muscle, with bilateral distribution in 2 cadavers.

Variations in the branching pattern of the posterior cord of brachial plexus were as follows, the appearance of two upper subscapular nerves was seen in five upper limbs (2 right and 3 left) with bilateral distribution in two cadavers. Common trunk for USN, TN, LSN, and AN was seen in only one right limb. Common trunk for TN, LSN, and AN was seen in 7 upper limbs (4 right and 3 left) with bilateral distribution in two cadavers. Common trunk for TN and LSN was seen in 3 upper limbs (1 right and 2 left) with bilateral distribution in one cadaver. Common trunk for LSN and AN was seen in 10 upper limbs (5 right and 5 left) with bilateral distribution in 2 cadavers.

Branches of medial cord did not show any variation pattern. 
Fig. 1: Absence of musculocutaneous nerve

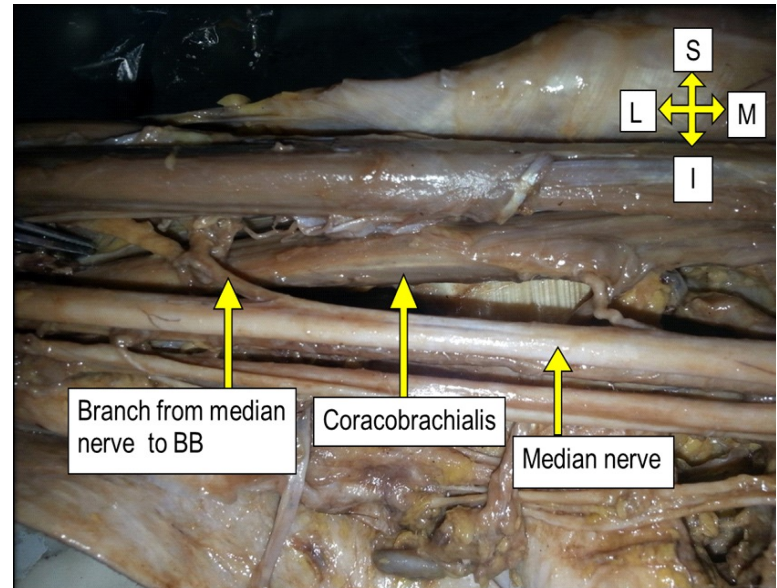

$\mathrm{S}=$ Superior $\mathrm{I}=$ Inferior $\mathrm{M}=$ Medial $\mathrm{L}=$ Lateral $\mathrm{BB}=$ Biceps brachii

Fig. 2: Musculocutaneous nerve not piercing coracobrachialis muscle

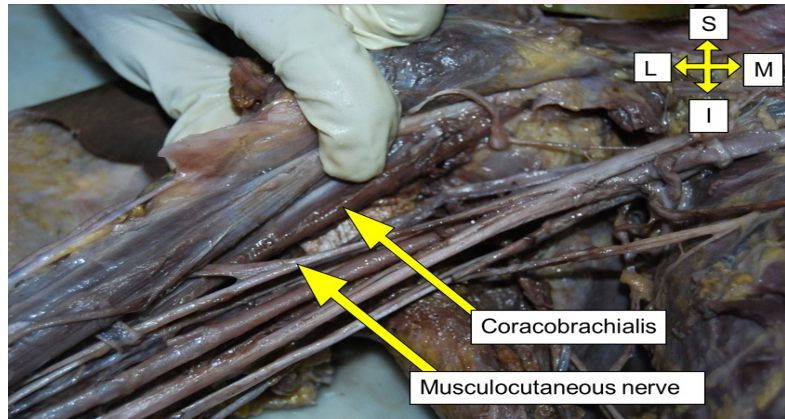

$\mathrm{S}=$ Superior $\mathrm{I}=$ Inferior $\mathrm{M}=$ Medial $\mathrm{L}=$ Lateral

Fig. 3: Communicating branch of musculocutaneous nerve with median nerve after piercing coracobrachialis muscle

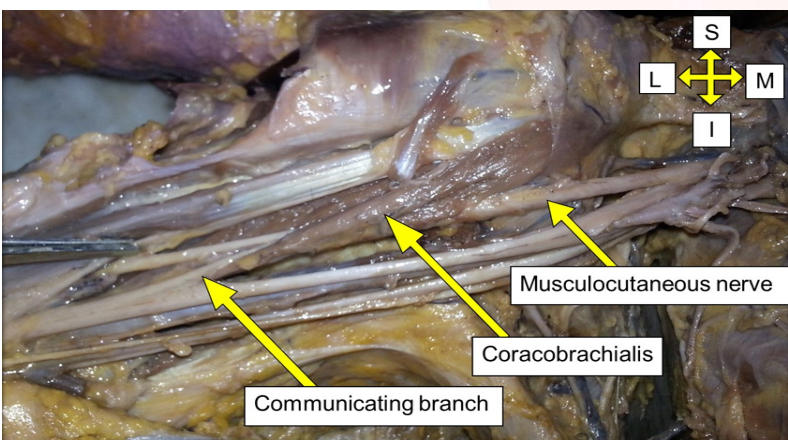

$\mathrm{S}=$ Superior $\mathrm{I}=$ Inferior $\mathrm{M}=$ Medial $\quad \mathrm{L}=$ Lateral

Fig. 4: Two upper subscapular nerves, axillary nerve and lower subscapular nerve arising as a common trunk.

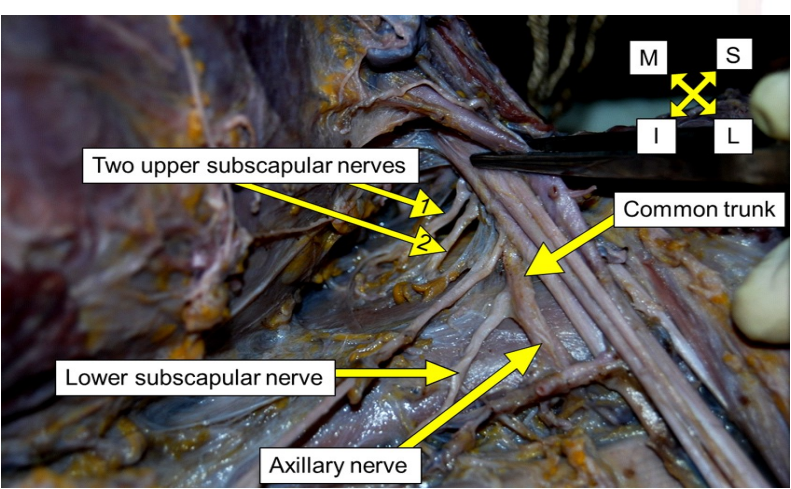

Fig. 5: Common trunk of thoracodorsal nerve, lower subscapular nerve and axillary nerve

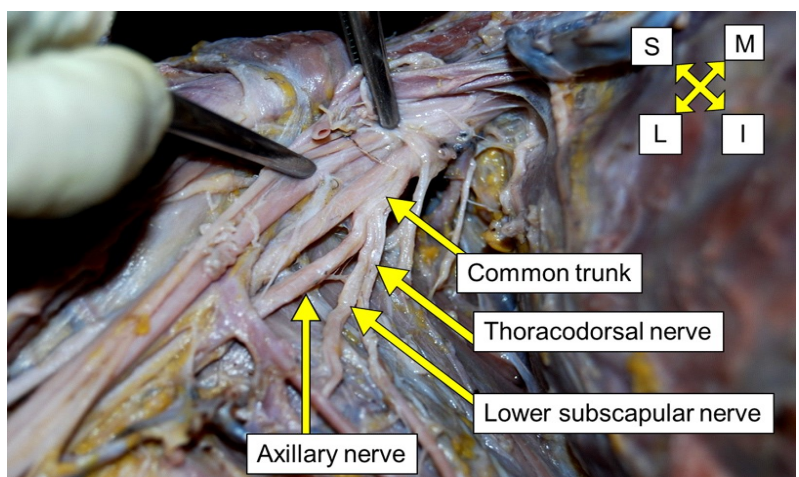

$\mathrm{S}=$ Superior $\mathrm{I}=$ Inferior $\mathrm{M}=$ Medial $\mathrm{L}=$ =Lateral

Fig. 6: Common trunk for upper subscapular nerve, thoracodorsal nerve, lower subscapular nerve, axillary nerve

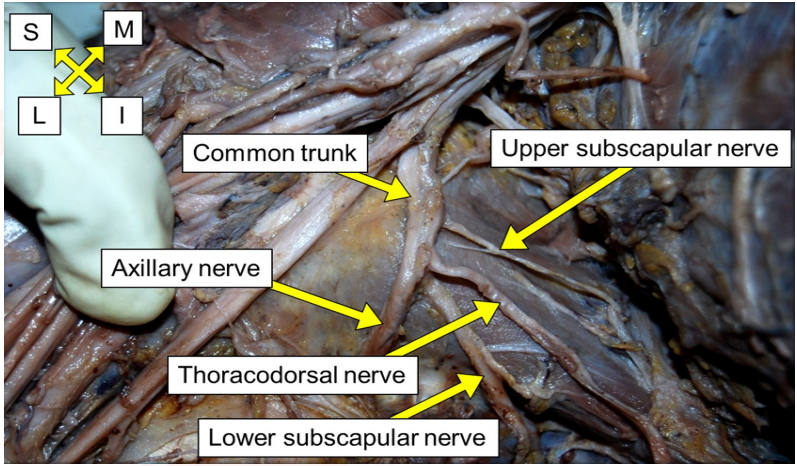

$\mathrm{S}=$ Superior $\mathrm{I}=$ Inferior $\mathrm{M}=$ Medial $\mathrm{L}=$ =Lateral

Fig. 7: Variation in the branches of posterior cord showing common trunk for thoracodorsal nerve and lower subscapular nerve

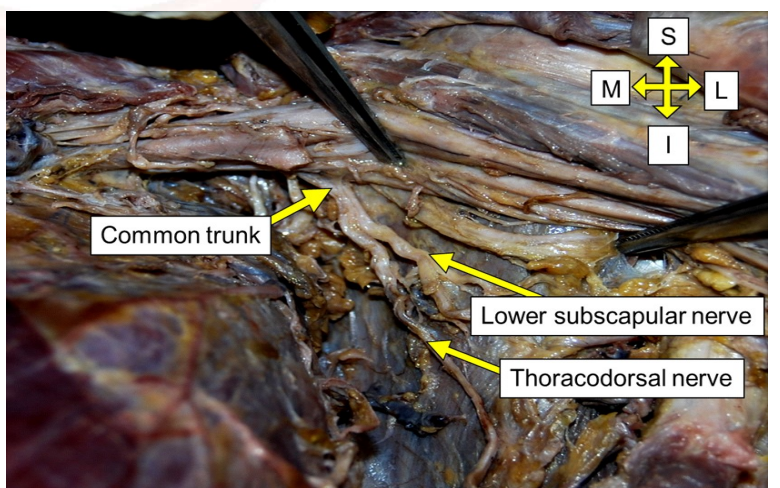

$\mathrm{S}=$ Superior $\mathrm{I}=$ Inferior $\mathrm{M}=$ Medial L=Lateral Fig. 8: Superior and inferior division of posterior cord and axillary arch muscles passing between two divisions

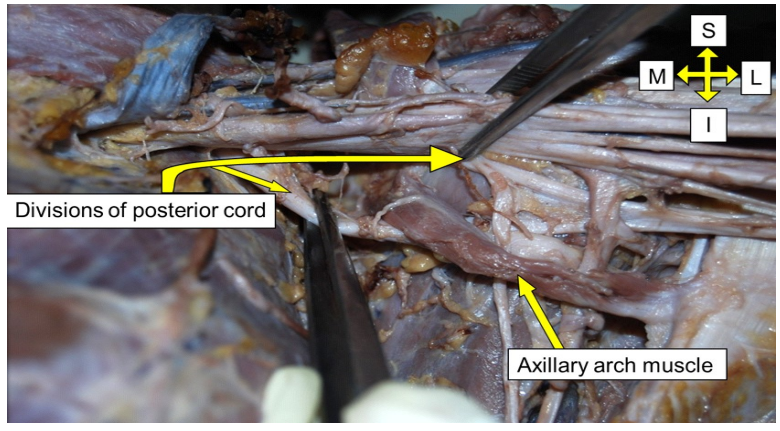

$\mathrm{S}=$ Superior $\mathrm{I}=$ Inferior $\mathrm{M}=$ Medial $\mathrm{L}=$ Lateral 
Table 1: Absence of musculocutaneous nerve.

\begin{tabular}{|l|c|}
\hline \multicolumn{1}{|c|}{ Authors } & $\begin{array}{c}\text { Percentage of absence of } \\
\text { musculocutaneous nerve }\end{array}$ \\
\hline Prasad rao P.V.V.(2001) & $8.33 \%$ \\
\hline Badawoud MH (2003) & $1.90 \%$ \\
\hline Beheiry EE (2004) & $1.70 \%$ \\
\hline Arora L, Dhingra (2005) & $15 \%$ \\
\hline Guttenberg et al. (2009) & $3.60 \%$ \\
\hline Present study & $3.51 \%$ \\
\hline
\end{tabular}

Table 2: Musculocutaneous nerve not piercing coracobrachialis.

\begin{tabular}{|l|c|}
\hline \multicolumn{1}{|c|}{ Authors } & Pecentage \\
\hline Rao H. (1955) & $9.33 \%$ \\
\hline Bergman R.A. (1988) & $22 \%$ \\
\hline Venierators and Anaguostopoulou (1998) & $1.89 \%$ \\
\hline Present study & $4.40 \%$ \\
\hline
\end{tabular}

Table 3: Variant pattern of communication between median nerve and musculocutaneous nerve (According to the Choi D. system of classification).

\begin{tabular}{|l|c|c|c|c|c|}
\hline \multicolumn{1}{|c|}{ Study } & Sample size & Pattern 1 & Pattern 2a & Pattern 2b & Pattern 3 \\
\hline Gegenbaur(1867) & 41 & 3 & 18 & 2 & 5 \\
\hline Testut(1883) & 105 & 6 & 29 & 0 & 1 \\
\hline Villar(1888) & 37 & 7 & 9 & 0 & 1 \\
\hline Vallois (1922) & 200 & 11 & 65 & 1 & 5 \\
\hline Hirasawa (1931) & $106-123$ & $2 / 123$ & $37 / 106$ & $0 / 106$ & $9 / 106$ \\
\hline Buch-Hansen(1955) & 75 & 2 & 5 & 0 & 0 \\
\hline Kosugi et al. (1992) & 75 & 3 & 26 & 9 & 5 \\
\hline Venieratos and & 158 & 0 & 22 & 0 & 0 \\
\hline Anagnostopoulou (1998) & 276 & 14 & 51 & 2 & 5 \\
\hline Choi D. (2002) & 114 & 0 & 23 & 0 & 0 \\
\hline Present study & & & \\
\hline
\end{tabular}

Table 4: Intercommunication between median nerve and musculocutaneous nerve.

\begin{tabular}{|l|c|}
\hline \multicolumn{1}{|c|}{ Name of the study } & Percentage \\
\hline Kerr A.J.(1918) & $28 \%$ \\
\hline Yang (1998) & $12.50 \%$ \\
\hline Chiarapattanakom (1998) & $16 \%$ \\
\hline Venierators and Anaguostopoulou(1998) & $13.90 \%$ \\
\hline Aktan (2001) & $10.40 \%$ \\
\hline Choi D.(2002) & $26.44 \%$ \\
\hline Fazan V.P.S.(2003) & $7.40 \%$ \\
\hline Beheiry EE (2004) & $5 \%$ \\
\hline Guttenberg et al. (2009) & $53.60 \%$ \\
\hline Present study & $20.91 \%$ \\
\hline
\end{tabular}

Table 5: Variations in the branches of posterior cords of the brachial plexus.

\begin{tabular}{|l|c|c|c|c|}
\hline \multicolumn{1}{|c|}{ Author } & $\begin{array}{c}\text { Common trunk } \\
\text { for LSN \& AN }\end{array}$ & $\begin{array}{c}\text { Common trunk } \\
\text { for LSN \& TN }\end{array}$ & $\begin{array}{c}\text { USN two in } \\
\text { number }\end{array}$ & $\begin{array}{c}\text { Two divisions of } \\
\text { posterior cord }\end{array}$ \\
\hline Ballesteros et al. (2007) & $31(54.4 \%)$ & $7(12.3 \%)$ & $12(21.1 \%)$ & - \\
\hline Fazan et al. (2011) & $29(54 \%)$ & $4(7.4 \%)$ & - & - \\
\hline Chaudhary P. et al. (2011) & $2(3.3 \%)$ & - & - & - \\
\hline Bhat K (2008) & - & - & - & $1(1.04 \%)$ \\
\hline Jamuna M (2010) & - & - & - & $1(2 \%)$ \\
\hline Present study & $10(8.8 \%)$ & $3(2.6 \%)$ & $5(4.3 \%)$ & $1(0.8 \%)$ \\
\hline
\end{tabular}

\section{DISCUSSION}

Absent musculocutaneous nerve: Le minor (1990) has reported an absence of musculocutaneous nerve and the lateral cord of brachial plexus gave muscular branches to coracobrachialis and biceps brachi [6].

Hollinshead (1982) [7] has stated that rarely the musculocutaneous nerve is not found and its various branches arise from the median nerve. The absence of musculocutaneous nerve was noted by Sud M and Sharma A (2000) [8], Le Minor (1990) [6], Nakata et.al (1997) [9] and Gumusburn (2000) [10].

Gumusburn (2000) have noted a bilateral absence of musculocutaneous nerve. Two branches from the lateral cord innervated the coracobrachialis muscle. The median nerve innervated the biceps brachii and brachialis muscle [10].

Prasad Rao PV and Chaudhary SC (2001) observed the musculocutaneous nerve to be absent in two cases out of 24 upper limbs. The area of supply of the musculocutaneous nerve was contributed by median nerve by giving both muscular and sensory branches [11].

Beheiry EE (2004) has noted the absence of musculocutaneous nerve in one limb (1.7\%) out of 60 upper limbs studied [12].

Guttenberg et al. (2009) in their study of 56 upper limbs have noticed the absence of musculocutaneous nerve in 2 (3.6\%) upper limbs [13].

Renata P. et al (2011) [14] observed the absence of the musculocutaneous nerve, with innervation of the anterior compartment of the muscles of the arm by the lateral root of the median nerve. This neural variant of the brachial plexus coexisted with a three-headed biceps brachii and an unusual loop around the axillary artery made by the medial cord of the brachial plexus.

The musculocutaneous nerve innervates muscles of the anterior compartment of the arm and the lateral margin of the forearm. The median nerve does not have any muscular branches in the arm. If the musculocutaneous nerve is absent, its fibers run in the median nerve [15, $10,14,16]$ and muscles of the anterior compartment of the arm are innervated by the median 
nerve $[15,11,8,10,16-19]$.

This anatomical variation may be explained by embryological development of the upper limb. Mesenchyme, which comes from the dorsolateral part of the somites, migrates and forms the muscles of a limb. At the same time, the mesenchyme is penetrated by the ventral primary rami of the appropriate spinal nerves, located opposite to the bud. Contact between nerves and muscle cells are necessary to provide mesenchymal condensation to form muscles. Nerves supplying the limbs are joined by connecting loops of nerve fibers to form plexuses. The ventral segmental branches unite to form median nerve which gives rise to musculocutaneous nerve. Any disturbances in these processes of development, during the 4th-7th weeks, lead to anatomical variations in the form of inappropriate innervation of muscles $[20,11]$.

Based on embryological development, an absence of the musculocutaneous nerve means the nerve did not branch from the lateral cord or from the median nerve, But its fibres ran in the median nerve $[15,10]$. As the nerves are named due to the course they take or the innervation, and not from their origin, it is reasonable to assume that the combined nerve was the median nerve carrying fibres of musculocutaneous nerve and a separate musculocutaneous nerve did not actually exist.

In the present study, 4 cases ( 2 on the right side and 2 on the left side) did not show a separate musculocutaneous nerve (Fig. 1). This variation of the absence of musculocutaneous nerve is compared with similar studies done as shown in table 1.

Musculocutaneous nerve not piercing coracobrachialis muscle: Hollinshead (1982) [7] quoting Rao et al. has described that $9.3 \%$ of musculocutaneous nerves did not pierce coracobrachialis muscle.

Normally the musculocutaneous nerve pierces the coracobrachialis muscle from its medial aspect at an approximate distance of $5 \mathrm{~cm}$ distal to the tip of the coracoid process. The musculocutaneous nerve may pass behind the coracobrachialis muscle without piercing it or remain attached for some distance to the median nerve or pass behind the biceps or may be accompanied by fibres from the median nerve as it transits coracobrachialis, less frequently the reverse occurs [21].

Rao et al, have described that $9.3 \%$ of musculocutaneous nerves did not pierce coracobrachialis muscle [11]. The percentage of cases where the musculocutaneous nerve did not pierce the coracobrachialis in the present study is compared with those of earlier studies and tabulated in table 2 .

The nerve not piercing the muscle can be explained on the embryological basis. During the $5^{\text {th }}$ week of embryonic life, the muscles of forelimb are developed from the mesenchyme of the paraxial mesoderm. The limb bud mesenchyme is reached by growing axons of spinal nerves. There are multiple possibilities for the route taken and the guidance of the developing axons, is regulated by expression of chemoattractants and chemorepellants in a highly co-ordinated site-specific fashion. Any alteration in signaling between the mesenchymal cells and neuronal growth cones can lead to significant variations. The above mentioned developmental anomalies for the axon to guide itself towards the coracobrachialis can lead to a situation where the musculocutaneous nerve does not pierce the coracobrachialis [22].

In cases where the musculocutaneous nerve does not pierce the coracobrachialis, the nerve has a superficial course in the upper arm and subsequently, it will be predisposed to injury by trauma or surgical procedures in this area. These cases are not prone to compression injury by coracobrachialis muscle [23].

In 5 limbs (4.4\%), in the present study, the musculocutaneous nerve did not pierce the coracobrachialis muscle (Fig. 2).

\section{Communication between median and muscu-}

locutaneous nerve: Musculocutaneous nerve frequently communicates with the median nerve. Communication between the musculocutaneous and the median nerves in the arm is considered as a remnant of phylogeny. Kosugi (1986) reported that there was one trunk equivalent to the median nerve in the thoracic limb of lower vertebrates (amphibians, reptiles, birds) [24].

Le Minor (1992) [6] noted 5 types of classifica- 
tion for communications between musculocutaneous nerve and median nerve:

Type 1 - No communication between the musculocutaneous nerve and median nerve

Type 2 - Fibres of the medial root of median nerve pass within the musculocutaneous nerve and join the median nerve in the middle of the arm

Type 3 - Lateral root fibres of median nerve pass through the musculocutaneous nerve for some distance and then separate from it to form the lateral root of median nerve

Type 4 - Musculocutaneous nerve fibres unite with the lateral root of the median nerve and after some distance, the musculocutaneous nerve arises from the median nerve

Type $\mathbf{5}$ - Absence of musculocutaneous nerve and all the fibres of musculocutaneous nerve pass through the lateral root of the median nerve and the muscles supplied by musculocutaneous nerve branch out directly from the median nerve Venierators and Anagostopoulou (1998) [25] classified the communication between the two nerves into 3 types:

Type 1 - Communication between musculocutaneous nerve and median nerve is proximal to the entrance of musculocutaneous nerve into the coracobrachialis

Type 2 - Communication is distal to the muscle

Type 3 - The nerve or communicating branch did not pierce the muscle

A study done by Atkan ZA et al (2001) showed that connections between the musculocutaneous nerve and median nerve were found in five arms. The connections were not bilateral in any cadaver [26].

Choi et al. (2002)[27] generally classified the communications between the musculocutaneous nerve and median nerve into three patterns:

Pattern 1 - Both the nerves are fused

Pattern 2 - One communicating branch between musculocutaneous nerve and median nerve

Pattern 3 - Two communicating branches between musculocutaneous nerve and median nerve

During the $5^{\text {th }}$ week of embryonic life [1], the muscles of forelimb are developed from the mesenchyme of the paraxial mesoderm. The limb bud mesenchyme is reached by growing axons of spinal nerves. The peripheral processes of the sensory and motor neurons grow in the mesenchyme, in different directions [28]. Significant variations in the nerve patterns may be a result of altered signalling between mesenchymal cells and neuronal growth cones or circulatory factors at the time of formation of brachial plexus [29].

In the present study, variations in the lateral cord were seen as the absence of the musculocutaneous nerve in 4 limbs (Fig.1); musculocutaneous nerve not piercing coracobrachialis in 5 upper limbs (Fig.2); communication between musculocutaneous and median nerve before piercing coracobrachialis muscle in 22 upper limbs and communication between musculocutaneous nerve and median nerve after piercing coracobrachialis muscle in one limb (Fig. 3).

In the present study as per the classification of Venieratos and Anagnostopoulou, out of 114 limbs, Type 1 was seen in 22 limbs; Type 2 was seen in 1 limb and Type 3 was not seen in any limb. Earlier studies and present study of communication between musculocutaneous nerve and median nerve are compared in table 3 and table 4.

\section{Variation in branches of the posterior cord:}

Fazan et al. (2003) [30] in their study gave a classical description of the origin of the thoracodorsal nerve, describing two different types including an axillary nerve origin and a radial nerve origin in $13 \%$ and $5.5 \%$ of cases respectively.

Tubbs et al. (2007) [31] in their study found 1.5\% of thoracodorsal nerve coming from the radial nerve.

A similar study by Ballesteros (2007) [32] had reported about thoracodorsal nerve variations. The thoracodorsal nerve originated from the posterior cord in 44 (78.6\%) cadavers in the study. Remaining 12 (21.4\%) cadavers had variations in the origin of thoracodorsal nerve; among which the origin from the radial nerve was reported in 5 (8.9\%), from the middle trunk in 2 (3.6\%) and from the axillary nerve in 5 (8.9\%) cadavers. Chaudhary P. et al. (2011) noted that the posterior cord showed normal branching 
pattern in 52 (86.67\%) limbs, the remaining 8 (13.33\%) showed variation in one form or the other. The branches of posterior cord like upper subscapular nerve, lower subscapular nerve, thoracodorsal nerve and the axillary nerve were seen to arise normally in $91.66 \%, 96.66 \%$, $96.66 \%$, and $98.33 \%$ of the limbs respectively. While the radial nerve had a normal origin in all of the limbs [33].

In the present study, variations in the posterior cord were seen as the presence of two upper subscapular nerves in 5 upper limbs (Fig. 4); Common trunk for upper subscapular nerve, thoracodorsal nerve, lower subscapular nerve, axillary nerve in one upper limb (Fig. 6); Common trunk for thoracodorsal nerve, lower subscapular nerve, axillary nerve in 7 upper limbs (Fig 5); Common trunk for lower subscapular nerve and axillary nerve in 10 upper limbs (Fig. 4); Common trunk for thoracodorsal nerve and lower subscapular nerve in 3 upper limbs (Fig. 7).

Two divisions of posterior cord of brachial plexus: Bhat K. et al (2008) [34] studied brachial plexus in 48 cadavers and noted a single case of the posterior cord variation in infraclavicular part of the brachial plexus. The posterior cord split into a thick posterior and thin anterior roots and enclosed the subscapular artery near its origin. After enclosing the subscapular artery, the two roots fused to continue as radial nerve.

The branches of the posterior cord like upper subscapular nerve arose from the main trunk of the posterior cord. Thoracodorsal nerve, lower subscapular nerve, and the axillary nerve have originated from the thick posterior root of the cord. The radial nerve, which was formed after the fusion of two roots of the posterior cord, gave rise to the nerves to a long and medial head of triceps. On the other hand, in the left axilla, the posterior cord did not show any variation.

Jamuna M (2010) [35] studied 50 upper limbs in 25 cadavers and noted a rare variation in the mode of termination of the posterior cord of the brachial plexus. The radial nerve was formed by the union of two divisions of the posterior cord and the axillary nerve was arising from one of those divisions.
In the present study, the posterior cord was divided into superior and inferior divisions, and an axillary arch muscle was noted passing in between these two divisions of the posterior cord. The thoracodorsal nerve was seen arising from superior division while inferior division gave rise to upper subscapular nerve, lower subscapular nerve, and axillary nerve. Both the division united to continue as radial nerve distally (Fig. 8). The variations in the branches of posterior cord were compared with previous studies as shown in table 5.

\section{CONCLUSION}

It is reasonable to believe that a thorough knowledge of variations of brachial plexus is binding during surgical exploration of axilla and arm during coracoid graft transfer surgery and in neurotisation and nerve grafting techniques.

In the present study, an attempt has been made to find out about the possible variations of the brachial plexus in Indian subjects with reference to its branching pattern. Though the variations mentioned may not alter the normal functioning of the limb of the individual, knowledge of the variations is of prime importance to be kept in mind, during surgical procedures. The restricted sample size was a limitation in the present study. Yet an earnest effort made in this study has opened new avenues for further research, which would provide guidelines for successful surgical interventions.

\section{ABBREVIATIONS}

USN: Upper subscapular nerve

TN: Thoracodorsal nerve

LSN: Lower subscapular nerve

AN: Axillary nerve

RN: Radial nerve

\section{ACKNOWLEDGEMENTS}

I would like to acknowledge the support rendered by Dr. P.S.Bhuiyan, Professor and Head Department of Anatomy, Dr. Lakshmi Rajgopal, Additional Professor of Department of Anatomy, Seth G.S. Medical college \& K.E.M hospital Mumbai and Dean Seth G.S. Medical college \& K.E.M hospital Mumbai for carrying out this study.

\section{Conflicts of Interests: None}




\section{REFERENCES}

[1]. Gupta S. Hand, Nerve Injury Repair. (monograph on the internet) e-medicine.[ cited 2016 may 31 ] Available from http://emedicine.medscape.com/article/ 1287077-overview.

[2]. Bannister LH, Berry MM, Collin P, Dyson M, Dussek JE, Fergusson MWJ. Nervous System, Brachial Plexus. In: Gray's Anatomy-The Anatomical Basis of Medicine and Surgery; $38^{\text {th }}$ ed. Churchill Livingstone; Edinburgh, 1995. P 1266-1274

[3]. Songcharoen P. Management of Brachial Plexus Injury In Adults. Scandinavian Journal of Surgery. 2008; 97: 317-323.

[4]. Abbas R., Hani A.-J., Lam F. Nerve injury associated with shoulder surgery. Current orthopaedics. 2008; 22: 284-288

[5]. Romanes GJ editor. Cunningham's Manual of Practical Anatomy. 15th edition. Oxford New York Tokyo: Oxford University Press, 1986;1: 22-32

[6]. Le Minor JM. A Rare Variant of the Median and Musculocutaneous Nerve In Man. Arch Anat Histol Embryol. 1990; 73:33-42.

[7]. Hollinshead WH. Anatomy for Surgeons. Vol3. The Back and limbs. 3rded. Haper \& Low, Philadelphia; 1982. P 220-223, 259-340, 797.

[8]. Sud M, Sharma A. Absence of Musculocutaneous Nerve and Innervation of Coracobrachialis, Biceps Brachii, and Brachialis from Median Nerve. J Anat Soc India. 2000; 42(2):176-7.

[9]. Nakata T, Tanaka SH. Absence of Musculocutaneous Nerve with Innervation of Coracobrachialis, Biceps and Lateral Border of Forearm. J Anat.1997;191:459.

[10]. Gumusburn E, Adigauzel E. A Variation of the Brachial Plexus Characterised by the Absence of Musculocutaneous Nerve- A Case Report. Surg Radiol Anat. 2000; 22: 63-5.

[11]. Rao PV,Chaudhary SC. Absence of Musculocutaneous Nerves: Two Case Reports. Clin Anat. 2001; 14:31-5.

[12]. Beheiry EE. Anatomical Variations of the Median Nerve Distribution and Communication in the Arm. Folia Morphol. 2004; 63(3): 313-318.

[13]. Guttenberg RAG, Ingolotti M. Classifying Musculocutaneous Nerve Variations. Clin Anat. 2009; 22: 671-83.

[14]. Renata P, Wiesiawa K-P, Jerzy A, Walocha Absence of the Musculocutaneous Nerve Associated with a Supernumerary Head of Biceps Brachii: A Case Report. Surg Radiol Anat. 2011; 33: 551-554.

[15]. Song WC, Jung HS, Kim HJ. Shin C, Lee BY, Koh KS. A Variation of the Musculocutaneous Nerve Absent. Yonsei Med J. 2003; 44(6):1110-1113.

[16]. Fregnani J, Macéa MI, Pereira CS, Barros MD, Macéa JR. Absence of the Musculocutaneous Nerve: A Rare Anatomical Variation with Possible Clinical-Surgical Implications. Sao Paulo Med J. 2008;126(5): 288-290.

[17]. Arora L, Dhingra R. Absence of Musculocutaneous Nerve and Accessory Head of Biceps Brachii: A Case Report. Indian J Plast Surg. 2005; 38:144-146.

[18]. Aydin ME, Kale A, Edizer M, Kopuz C, Demir MT, Corumlu U. Absence of the Musculocutaneous Nerve
Together with Un-usual Innervation of the Median Nerve. Folia Morphol. 2006; 65(3): 228-231.

[19]. Ihunwo AO, Osinde SP, Mukhtar AU. Distribution of Median Nerve to Muscles of the Anterior Compartment of the Arm. Cent Afr J Med. 1997; 43: 359-360.

[20]. Uzun A, Leonard L, Seelig J. A Variation In The Formation Of The Median Nerve: Communicating Branch Between the Musculocutaneous and the Median Nerve in Man. Folia Morphol. 2001; 60: 99101.

[21]. Kaus M, Wotowicz Z. Communicating Branch Between Musculocutaneous and Median Nerves in Humans Folia Morphol. 1995; 54: 273-7.

[22]. Chauhan R, Roy TS. Communication Between Median and Musculocutaneous nerve-A case report. J Anat Soc India. 2002; 52(1): 72-5

[23]. Badawoud MH. Study of the Anatomical Variations of the Musculocutaneous Nerve. Neuro Sciences, 2003; 8(4).

[24]. Kosugi L, Mortia T, Yamashita H. Branching Pattern of the Musculocutaneous Nerve in Case Possessing Normal Biceps Brachii. Jikeakai Med J. 1986; 33: 63-71.

[25]. Venieratos D, Anangnastopoulou S. Classification of Communication Between the Musculocutaneous and Median Nerves. Clinical Anatomy.1998; 11:327331.

[26]. Atkan ZA, Ozturk L, Bilge O, Ozer MA, Pinar YA. A Cadaveric Study of the Anatomic Variations of the Brachial Plexus Nerves in the Axillary Region and Arm. Turk J Med Sci. 2001; 31: 147-50.

[27]. Choi D, Rodriguez- Niedenfuhr M, Vazquez T, Parkin I, Sanudo JR. Patterns Of Connections Between the Musculocutaneous and Median Nerves in the Axilla and Arm. Clin Anat. 2002;15(1): 11-7.

[28]. Brown MC, Hopkins WJ, Keynes RJ. Axon Guidance and Target Recognition. Cambridge: Cambridge University Press. 1991; P.46-66.

[29]. Sannes HD, Relh TA, Harris WA. Development of Nervous System. New York: Academic Press.2000; p. 189-97.

[30]. Fazan VPS, Amadeu AS, Caleffi AL, Rodrigues OA. Brachial Plexus Variations in Its Formation and Main Branches. Acta Cirurgica Brasileria. 2003; 18: 14-8.

[31]. Tubbs RS, Loukas $M$, Shahid K, Judge T, PinyardJ, Shoja MM, Slappey JB, McEvoy WC, Oakes WJ. Anatomy and Quantitation of the Subscapular Nerves. Clin Anat. 2007; 1.

[32]. Ballesteros LE, Ramirez LM. Variations of the Origin of Collateral Branches Emerging from the Posterior Aspect of the Brachial Plexus. Journal of brachial plexus and peripheral nerve injury. 2007; 2:14

[33]. Chaudhary P, Singla R, Kalsey G, Arora K. Branching Pattern of the Posterior Cord of the Brachial Plexus. Journal of Clinical and Diagnostic Research. 2011; 5(4): 787-790.

[34]. Bhat K, Girijavallabhan V. Variation in the Branching Pattern of Posterior Cord of Brachial Plexus. Neuroanatomy 2008; 7:10-11.

[35]. Jamuna M. A Rare Variation in the Mode of Termination of Posterior Cord of Brachial Plexus. International Journal of Anatomical Variations. 2010; 3 : 95-96. 